\title{
THE PERFECT TENSE AND THE FORMS OF PAST PARTICIPLE IN OLD ENGLISH
}

\author{
Vladimir A. Bondar \\ Saint Petersburg State University, Saint Petersburg, Russia
}

\begin{abstract}
The paper deals with peculiarities of using the possessive verb habban + inflected participle II. On the basis of the sample of Old English prose texts we analyze the frequency distribution of instances throughout the periods (dates) which manuscripts from the corpus belong to. We also provide a detailed analysis of semantic and syntactic properties of inflected participles used as part of the construction ' $h a b b a n+$ participle II'. Assuming that the semantics of this construction with both inflected and uninflected participles was meaningful, it is suggested to make distinction between the meaning of ' habban + participle II' with inflected participles and with uninflected participles as similar to the semantic shades which can be traced when adjectives are used either attributively or predicatively. The proposed distinction between inflected and non-inflected participles used within the investigated construction retains its resultantstate semantics but brings in certain distinctive shades of meaning in characteristics of the subject and/or object. In particular, an inflected participle indicates durative immanent features of the subject and/or object (similar to attributive characteristics of adjectives), whereas a non-inflected participle describes the subject and/or object based on the model of predicative usage of adjectives emphasizing its contextual, ad hoc, temporary feature.
\end{abstract}

Key words: perfect tense, statal perfect, semantics, participle forms, morphology, syntax, Old English.

Citation. Bondar V.A. The Perfect Tense and the Forms of Past Participle in Old English. Vestnik Volgogradskogo gosudarstvennogo universiteta. Seriya 2, Yazykoznanie [Science Journal of Volgograd State University. Linguistics], 2018, vol. 17, no. 4, pp. 55-67. (in Russian). DOI: https://doi.org/10.15688/jvolsu2.2018.4.5

УДК 811.111 ’01

Дата поступления статьи: 01.06.2018

ББК 81.432.1-03

Дата принятия статьи: 02.07.2018

\section{ПЕРФЕКТ И ФОРМЫ ВТОРОГО ПРИЧАСТИЯ В ДРЕВНЕАНГЛИЙСКОМ ЯЗЫКЕ}

\author{
Владимир Анатольевич Бондарь \\ Санкт-Петербургский государственный университет, г. Санкт-Петербург, Россия
}

\begin{abstract}
Аннотация. В данной статье рассматриваются особенности употребления конструкции, состоящей из посессивного глагола habban и флектированного причастия II. На основе выборки из корпуса древнеанглийских прозаических текстов проведен анализ распределения частотности примеров по периодам, к которым принадлежат дошедшие до нас рукописи, и описаны семантико-синтаксические характеристики флектированных причастий в рамках конструкции «habban + причастие II». С учетом того, что семантика «habban + причастие II» как с флектированными, так и с нефлектированными причастиями имела результативный характер, предлагается различать значения конструкции с указанными причастными формами по аналогии с семантическими различиями, которые прослеживаются при атрибутивном и предикативном употреблении прилагательных. Установлено, $\underset{0}{\infty}$ что основанием выбора флектированного или нефлектированного причастия в рамках результативной конструкㄱ. ции «habban + причастие II» являлся признак субъекта-объекта: причастие с флексией указывало на длительную, имманентную характеристику описываемого предмета (аналогично атрибутивному прилагательному), а без нее - на ситуативный, временный признак предмета (аналогично предикативному прилагательному). Показано, 疍 что выявленная тенденция действовала в рамках древнеанглийского языка при сохранении флективной системы у 웡 прилагательных и существительных и прекращала свое действие к концу древнеанглийского периода, отражая () изменения морфологической системы языка.
\end{abstract}


Ключевые слова: перфект, результатив, семантика, причастные формы, морфология, синтаксис, древнеанглийский язык.

Цитирование. Бондарь В. А. Перфект и формы второго причастия в древнеанглийском языке // Вестник Волгоградского государственного университета. Серия 2, Языкознание. - 2018. - Т. 17, № 4. - С. 55-67. - DOI: https://doi.org/10.15688/jvolsu2.2018.4.5

\section{Вводные замечания}

В истории развития перфекта в английском языке не вызывает сомнений тот факт, что его источником послужило сочетание посессивного глагола habban (иметь) со вторым причастием от переходных глаголов. При этом последнее согласовывалось с прямым дополнением по роду, числу и падежу, что являлось одним из бесспорных доказательств отсутствия грамматикализации посессивного глагола на ранних этапах развития английского языка и статуса конструкции «habban + причастие II» как относительно свободного сочетания. Проблемы в интерпретации конструкции возникают, когда наряду с флектированной формой причастия употребляется нефлектированный вариант:

(1) pa hæfde he me gebundenne mid pære wynsumnesse his sanges... (Во:22.50.8.913) - 'тогда он меня сковал (досл. 'имел меня скованным') прелестью своего пения...';

(2) Darius hæfde gebunden his agene mægas mid gyldenre racentan (Or3:9.70.7.1374) - 'Дарий связал (досл. 'имел связанными') своих собственных сородичей золотыми цепями'.

Так, Дж. Ласски предлагает рассматривать случаи, аналогичные (1), как неграмматикализированный результатив с адъективным причастием, а случаи, аналогичные (2), - как полноправный перфект с глагольным причастием [Lussky, 1922, p. 39]. Заранее отметим вполне справедливое замечание исследователя: если в древнеанглийском никакого различия, кроме как риторического (мелодика предложения, поэтическая вольность), между двумя формами причастий в анализируемой конструкции не было, то почему такой свободой не пользовались прилагательные [Lussky, 1922, p. 39]?

Однако, как показал на различных примерах Б. Митчелл, такой подход противоречит фактическому материалу: в практически одинаковых контекстах встречаются примеры с одной и той же глагольной лексемой, но в разных причастных формах. Кроме того, в одной синтагме с двумя причастиями, соединенными союзом and (и), используются одновременно флектированная и нефлектированная формы [Mitchell, 1985, p. 283-285]. Казалось бы, интуитивно верное разграничение функционально-семантических характеристик двух форм второго причастия в конструкции с посессивным глаголом, предложенное Дж. Ласски, в действительности оказывается неправильным: сложно представить, что перфект и результатив могут употребляться в контекстах с однородными причастиями.

Удивительно, но данное противоречие специалисты по истории английского перфекта старательно обходили стороной, по умолчанию полагая, что примеры с флектированной формой, по крайней мере, на ранних этапах развития английского языка не могли быть чем-то иным, кроме как результативом. В фундаментальном труде по истории английского языка «The Cambridge history of the English language» в разделе, посвященном синтаксису, Э. Трауготт аккуратно касается данной темы (по ее мнению, трансформация конструкции с habban в вербальный комплекс была частично завершена в древнеанглийском), высказывая предположения о возможных причинах отпадения флексий в причастиях: сначала такие изменения могли произойти в конструкциях с дополнениями в ср. р. ед. ч., имевшими нулевое окончание, а потом распространились и на остальные контексты [Traugott, 1992, p. 192-193]. Тем не менее без ответа остается вопрос о том, как рассматривать на синхроническом уровне в дошедших до нас древнеанглийских текстах соотношение контекстов с разными формами причастий.

Анализируя развитие конструкции с посессивным глаголом в германских языках, О.А. Смирницкая различает внутри нее две формы синтаксической связи: атрибутивную и предикативную, а древнейшим прототипом конструкции, по ее мнению, «следует считать именно многозначную конструкцию с преди- 
кативно-атрибутивной формой связи» [Смирницкая, 1965, с. 7]. В ходе анализа древнеанглийского материала автор приходит к выводу о том, что противопоставление по атрибутивности и предикативности играло второстепенную роль в развитии перфекта. Отсутствие флектированных форм причастий едва ли можно рассматривать как прямое доказательство синтаксической неразложимости анализируемой конструкции, а «потеря причастием флексии свидетельствует лишь о возникновении новых синтаксических связей внутри сочетаний "habban + причастие II”» [Смирницкая, 1965, p. 12].

В последнее время в работах по истории английского перфекта исследователи отстаивают точку зрения, в соответствии с которой в древнеанглийском широко развит перфект, а момент перехода результатива (формы с флектированным причастием) в эту форму необходимо относить к дописьменному периоду [Johannsen, 2016; Lee, 2004; Łęcki, 2010; Wischer, 2004]. В рамках данной концепции с довольно радикальным предложением выступила И. Вишер, которая считает, что флексии причастий, входивших в эту конструкцию, не играли никакой роли, то есть семантических различий между двумя типами конструкций не было. В защиту своего тезиса автор приводит следующие аргументы: превалирование нефлектированных форм (в корпусе И. Вишер лишь в $10 \%$ контекстов представлены флектированные причастия); наличие примеров, в которых за объектом следуют причастия в двух разных формах; аналогическое расширение окончания м. р., вин. п., мн. ч. (-e) на ср. p., мн. ч., где должно быть нулевое окончание: [WHom 20.3:30.1766] \& we habbad Godes hus inne \& ute clone berypte - 'мы полностью осквернили дома Бога внутри и снаружи' (здесь и далее перевод примеров наш. - В. Б.); наличие адъективного окончания в контекстах с динамическим прочтением конструкции: [BIHom 2]:15.24.201] pin agen geleafa pe haefp gehaeledne - 'твоя собственная вера тебя излечила'; отсутствие окончания у явно адъективных причастий: ÆLet 1 (Wulfsige X a) B1.8.1 [0098 (91)] gyf he cenigne gylt ungebet haef - 'если у него есть неискупленный грех'. Подводя итог, исследователь утверждает, что наличие нефлектированных форм можно рассматривать как лишенный всякого значения осколок предыдущего состояния (a meaningless residue of a former state) [Wischer, 2004, p. 244-246].

Отсутствие единой точки зрения по данному вопросу приводит к курьезным случаям, когда данный И. Вишер пример из гомилий Вульфстана с расхождением между требуемой и фактически употребленной флексиями причастия, другим автором рассматривается как доказательство того, что конструкция с посессивным глаголом и флектированным причастием в древнеанглийском языке не являлась перфектом: berypte имеет адъективный характер именно благодаря наличию флексии, само причастие находится в позиции после дополнения, а посессивный глагол полностью сохраняет свое лексическое значение (конструкция выдвигает на первый план оскверненное состояние домов Бога, а само действие осквернения оттесняется на задний план и логически выводится из данного состояния [Yao, 2015, p. 249]).

\section{Материал и цели исследования}

Для выявления статуса конструкции habban с флектированным причастием и характеристик ее отношения к аналогичным примерам без флектированных причастий мы проанализируем примеры, полученные методом сплошной выборки из синтаксически размеченного корпуса древнеанглийской прозы (The York-Toronto-Helsinki Parsed Corpus of Old English Prose). Тексты этого корпуса относятся к разным жанрам и принадлежат к одному из четырех периодов: до 850 гг., 850950 гг., 950-1050 гг., 1050-1150 годы. Мы не только рассмотрим синтаксические особенности (модели расположения элементов конструкции относительно друг друга), но и проанализируем семантические характеристики глаголов, используемых в формах флектированнных причастий. Основной задачей исследования, таким образом, является выяснение функциональных особенностей флектированных причастий в рамках конструкции «habban + причастие II», семантики конструкции, а также доказательной силы аргументов, высказанных И. Вишер.

Общее количество примеров в нашей выборке 138 , что составляет $9,5 \%$ от общего числа примеров «habban + причастие II» (1 454) 
и в целом совпадает с количественными данными в выборке И. Вишер (10 \%). На этих показателях основывается статистика, отражающая синтаксические характеристики конструкции и хронологическую дистрибуцию анализируемых причастий. Однако, как показано далее, этот количественный аргумент едва ли можно использовать в качестве доказательства отсутствия функциональной нагрузки у флектированных причастий.

Для дальнейшего (семантического) анализа из 138 примеров мы исключили повторы глагольных лексем и контексты, где конструкция «habban + причастие II» используется с модальными глаголами, например:

(3) ne mihte lencg habban his handa astrehte (ÆLS [Pr Moses]:16.2878) - 'не мог долго держать свои руки распростертыми';

или выступает в качестве каузатива, например:

(4) he sceolde đone Godes alter habban uppan aholodne (CР [Cotton]:33.216.18.26) - 'он должен алтарь Бога выдолбить наверху'.

(Полный обзор всех примеров habban в каузативном значении см. в [Kilpiö, 2013]). Таким образом, семантическому анализу будут подвергнуты 93 глагольные лексемы.

\section{Хронологическая и количественная характеристики конструкции}

Флектированные причастия встречаются в текстах, относящихся ко всем вышеуказанным периодам, за исключением самого раннего (до 850 гг.). В количественном отношении их распределение в нашей выборке выглядит следующим образом: период 850-950 гг. 50 употреблений $(36 \%), 950-1050$ гг. 28 (20\%), 1050-1150 гг. - 60 (44 \%). Приведенные данные косвенно свидетельствуют о тенденции к сокращению употребления флектированных причастий в анализируемой конструкции. Так, если в текстах IX в. зафиксировано $36 \%$ примеров, то столетие спустя 20 \%. Превалирование флектированных причастий в XI-XII вв. объясняется тем, что к данному периоду относятся тексты, которые были написаны в ранние эпохи (IX и X вв.), но дошли до нас в составе поздних рукописей, где не исключены ошибки, сделанные и в ре- зультате неправильной интерпретации, вызванной языковыми процессами, проходившими на стыке древнеанглийского и среднеанглийского периодов.

Из 93 анализируемых лексем 42 глагола (45 \%) использованы исключительно в форме флектированного второго причастия, в то время как остальные 51 (55 \%) зафиксированы в обеих формах. При этом из данных корпуса очевидно, что доминируют нефлектированные формы практически всех лексем. Например, распространенная в текстах 850-950 гг. лексема ge-sellan (продавать, отдавать) используется без флексии 9 раз, а во флективной форме 1 раз - в переводе «Утешение философией» Боэция:

(5) hi me habbad gesealdne hiora wlencum (Во:7.17.31 286) - 'они меня отдали своей пышности'.

Аналогичное этому соотношение характерно и для периода 950-1050 гг.: глагол don (делать) представлен 22 нефлектированными формами и 1 флектированной формой - в тексте перевода Семикнижия:

(6) Bearnleasne ge habbađ me gedonne (Gen:42.36.1793) - 'бездетным вы меня сделали' (досл. 'бездетным вы имеете меня сделанным').

\section{Синтаксическая характеристика}

Рассмотрим, в каком окружении употребляются флектированные формы второго причастия. При однородных причастиях, соединенных союзом and (и) используются либо 2 флектированные формы, либо сочетание флектированной и нефлектированной форм (2 нефлектированные формы - довольно распространенное явление и здесь в расчет не принимается):

(7) ac se anwealda hæfđ ealle his gesceafta swa mid his bridle befangene $\&$ getogene $\&$ gemanode... (Во:21.49.2.883) - 'но Всемогущий все свои создания как своей уздой схватил и сдержал и поддерживал...';

(8) pu pe buten ælcere wæmmunge and buten flite us hæe fest ealle ofercumene and genyđered? (Nic [C]:313.305) - 'ты, кто без какого-либо загрязнения и без борьбы всех нас побеждаешь и подчиняешь? ‘ (досл. 'имеешь побежденными и подчиненными'). 
В нашей выборке зафиксировано 3 примера, аналогичных (8). Каждый из них относится к одному из периодов (850-950 гг., 950-1050 гг. и 1050-1150 гг.) соответственно. Взаимное расположение флектированного и нефлектированного причастия может варьироваться. При этом количество случаев с двумя флектированными причастиями в 3 раза больше. Из 9 примеров 2 относятся к периоду 850-950 гг., 2 - к периоду 950-1050 гг. и 5 употреблены в текстах 1050-1150 гг. В 5 примерах перед вторым причастием используется прямое или предложное дополнение. В тех контекстах, где употребляется 2 конструкции, соединенные сочинительным союзом, в первом случае используется флектированная форма, во втором - нефлектированная. Всего обнаружено 2 таких примера, один из которых относится к периоду 850-950 гг., другой к $950-1050$ гг.:

(9) for đon pa feawan pe pær ut opflugon hæfdon eft pa burg gebune, \& hæfdon Thebane, Creca leode, him on fultum asponon (Or:_ 3:1.53.20.1025) - 'из-за тех немногих, которые оттуда убежали, и затем овладели тем городом и на свою сторону переманили фиванцев, греческий народ';

(10) and cyddon pæt pa hæpenan hæfdon hi besetene, and ofslagen hæefdon sum pusend manna (Maccabees:389.5094) - 'и рассказали, что язычники их осадили и убили тысячу человек’.

В более широких контекстах (в рамках сложносочиненного или сложноподчиненного предложения) также фиксируется параллельное употребление флектированной и нефлектированной форм:

(11) And sona swa pæt wæs pæt hi swa gedon hæfdon, ba hæfdon hy forworhte hy sylfe... (WHom 6:48.273) - 'И вскоре, как только они таким образом поступили, тогда они себя погубили...'

Из 10 подобных (11) примеров в нашей выборке 6 относятся к периоду 1050-1150 гг. и 4 - к периоду 850-950 годов. Большинство случаев приходится на употребление согласованных флектированных причастий, в то время как совместное употребление конструкций с обеими формами причастий в рамках более широкого контекста в основном относится к позднему периоду.
Далее рассмотрим позиционные особенности флектированных причастий по отношению к другим элементам конструкции в рамках предложения. Это расположение элементов уже было описано в ряде работ. Здесь стоит упомянуть о результатах, полученных в [Mitchell, 1985; Wischer, 2004], которые мы затем сравним с нашими данными. Важно также иметь в виду, что причастие, согласованное с дополнением ср. p. ед. ч., имеет нулевую флексию. Однако, как отмечает Б. Митчелл, едва ли существует какой-нибудь смысл проводить детальное разграничение между примерами с нулевой флексией и нефлектированными причастиями [Mitchell, 1985, p. 284].

В работе исследователя выделены 6 моделей распределения элементов habban, дополнения и второго причастия. Две из них выделяются для безобъектных конструкций. При этом автор отмечает, что флектированные причастия встречаются во всех моделях, кроме объектных - PP + HAVE + Obj, $\mathrm{PP}+\mathrm{Obj}+$ $H A V E$ (с дополнением в вин. п.) - и 2 безобъектных моделей - PP + HAVE и HAVE + PР. Митчелл отмечает, что все примеры, в которых реализуются объектные модели, включают прямые дополнения в вин. п. [Mitchell, 1985, p. 282-283]. В целом автор приходит к выводу, что ни в прозе Альфреда, ни в текстах Эльфрика, ни в поэтических, ни в прозаических текстах анализируемая конструкция не обладает ни фиксированной формой, ни фиксированной функцией [Mitchell, 1985, p. 291]. Однако выборка Б. Митчелла основана не на корпусных данных, поэтому им не были учтены примеры с флектированным причастием в род. п.:

(12) \& pa, æfter pan pe he hæfde unrim manna gehæledre \& geclænsedra \& deaddra awehte (HomS 24.1 [Scragg]:38.14) - 'и после того, как он бесчисленное множество людей вылечил, очистил и воскресил из мертвых',

и с прямым дополнением, выступающим в роли обстоятельства места:

(13) ...pe on đam scræfe tile hwile gereste hæfdon (LS 34 [SevenSleepers]:390.284) - '...которые в пещере должное время отдыхали',

о котором речь пойдет в следующем разделе. 
На основе более обширной, чем у Б. Митчелла, выборки из корпуса текстов типы дополнений, модели расположения элементов конструкции «habban + причастие II» и их частотность рассматривает И. Вишер. Самой распространенной моделью является $\mathrm{Obj}+\mathrm{PP}+H A V E(32 \%)$, характерная для придаточных предложений; менее частотны $H A V E+\mathrm{Obj}+\mathrm{PP}(23 \%)$, характерная для главного предложения, $H A V E+\mathrm{PP}+\mathrm{Obj}(20 \%)$, $\mathrm{Obj}+H A V E+\mathrm{PP}(15 \%) ;$ низкую частотность имеют $\mathrm{PP}+H A V E+\mathrm{Obj}(4 \%)$ и 2 безобъектных модели - HAVE + PР (3 \%) и РP + HAVE (2\%) [Wischer, 2004, p. 245].

Каковы модели расположения элементов в рамках конструкции с флектированными причастиями в нашей выборке и как они соотносятся с данными, приведенными в работах Б. Митчелла и И. Вишер? Нами было выделено 3 вида контекстов: главное, придаточное и простое предложения (к последнему виду мы будем относить также примеры сложносочиненных предложений). В каждом из них представлены несколько моделей расположения элементов: в простом предложении -17 , в главном - 6 , в придаточном - 18. Представим наиболее распространенные модели, где $\mathrm{S}$ - подлежащее, HAVE посессивный глагол, $\mathrm{PP}$ - флектированное причастие, $\mathrm{Obj}$ - дополнение, ObjDir - прямое дополнение, ObjInd - косвенное дополнение, ObjPrep - предложное дополнение.

Как видно из таблицы, флектированное причастие в наиболее распространенных случаях находится в постобъектной позиции за исключением 3 примеров в главном предложении. Предобъектная позиция фиксируется в менее частотных моделях. Такое располо- жение флектированного причастия встречается уже в ранних текстах короля Альфреда (период 850-950 гг.). Вполне возможно, что данные примеры отражают происходившие сдвиги в порядке слов древнеанглийского предложения. Позиция флектированного причастия в предложении не отличается от той, которая наблюдается у нефлектированных причастий и не нарушает общих требований к порядку слов (см. данные выборки И. Вишер). Кроме того, в нашей выборке встречаются примеры, которые отсутствуют у Б. Митчелла, в частности употребления причастия в род. П. и несколько случаев с 2 дополнениями: одно из которых (как правило, предложное) выносится в позицию после посессивного глагола, а другое (как правило, прямое) - перед причастием.

Для флектированного причастия наиболее характерны 2 позиции по отношению к другим элементам конструкции «habban + причастие II»: рамочная (с дополнением между посессивным глаголом и причастием) и контактная (последовательное расположение посессивного глагола и причастия) в разных соотношениях (причастие может стоять до или после habban) и типах предложений. Логично предположить, что контактная позиция способствовала трансформации результативной семантики конструкции в перфектную, но поскольку данная позиция встречается как в ранних, так и поздних произведениях и в разных типах предложений, едва ли справедливо делать вывод о влиянии изменения порядка слов на семантику конструкции. Здесь же следует привести мнение О.А. Смирницкой, которая на основании анализа древнеанглийских текстов, начиная с самых ранних и заканчивая раннесреднеанглийскими, приходит к заключению,

\section{Расположение элементов конструкции «habban + причастие II» в предложениях разных типов}

\begin{tabular}{|c|l|c|}
\hline Tип предложения & \multicolumn{1}{|c|}{$\begin{array}{c}\text { Расположение } \\
\text { элементов конструкции }\end{array}$} & $\begin{array}{c}\text { Количество } \\
\text { примеров }\end{array}$ \\
\hline \multirow{2}{*}{ Простое } & but S HAVE Obj PP & 13 \\
\cline { 2 - 3 } & but S Obj HAVE PP & 6 \\
\cline { 2 - 3 } & S HAVE Double Obj PP & 4 \\
\hline \multirow{2}{*}{ Главное } & HAVE S PP Double Obj & 3 \\
\cline { 2 - 3 } & S HAVE Obj PP & 2 \\
\cline { 2 - 3 } & S HAVE ObjInd ObjDir PP & 22 \\
\hline \multirow{2}{*}{ Придаточное } & when S HAVE Obj PP & 12 \\
\cline { 2 - 3 } & when S Obj PP HAVE & 4 \\
\cline { 2 - 3 } & how S ObjDir HAVE PP ObjPrep & \multicolumn{2}{|l}{} \\
\hline
\end{tabular}


B.A. Бондарь. Перфект и формы второго причастия в древнеанглийском языке

что контактное расположение посессивного глагола и причастия не может быть объяснено распадом рамочной конструкции. По мнению автора, идиоматизация перфекта, наоборот, способствовала распространению нового порядка слов [Смирницкая, 1965, с. 13]. Исследователь не исключает, что мы имеем дело с двумя параллельными процессами (идиоматизация перфекта и изменение порядка слов), находящимися во взаимной зависимости и вызванные разными причинами.

Вывод о том, что флексии в причастиях носили формальный характер и были лишены значения, сделанный на основании неправильного употребления флектированного причастия в примере из Вульфстана, является явным преувеличением. Во-первых, в примере \& we habbad Godes hus inne \& ute cloene berypte флексия -e в berypte может быть опиской, вызванной влиянием 3 подряд стоящих наречий с флексией -e: inne, ute, claene. Во-вторых, данный пример единичен и зафиксирован в рукописи, которая относится к позднедревнеанглийскому периоду. Следовательно, нельзя исключить возможность ошибки при переписывании, поскольку писец мог не использовать в своей речи флектированные формы причастий с анализируемой нами конструкцией, а распад флексий как в системе существительных, так и в системе прилагательных мог привести к путанице. В-третьих, если бы гипотеза И. Вишер была верна, то аналогичные примеры мы находили бы уже в ранних текстах, но в прозе Альфреда (как и в поздних текстах Эльфрика) согласование имеет стабильный характер без всевозможных ошибок:

(14) Swa swa wildu hors, đonne we hie æresđ gefangnu habbađ, we hie đacciađ \& straciad mid bradre hanđa (СР:41.303.7.2013) - 'как и дикие лошади, когда мы их сначала поймаем (досл. 'имеем пойманными'), мы их похлопываем и гладим открытыми ладонями'.

В примере (14) из текста «Пастырское попечение» (период 850-950 гг.) причастие gefangnu соотносится с существительным hors cp. p., мн. ч, о чем свидетельствует флексия -u.

В исследованном материале имеются случаи употребления абстрактного существительного в качестве подлежащего с конструкцией «habban + причастие II»:
(15) Loca nu; pin agen geleafa pe hafp gehoeledne (HomS 8 [BlHom 2]:15.24.201) - 'Вот смотри, твоя собственная вера тебя имеет излеченным'

Мы полагаем, что pin agen geleafa (твоя собственная вера) используется метафорически как воплощение некой высшей силы, силы наделенной способностью творить чудеса, как проявление Всевышнего и тем самым создается возможность для употребления глагола обладания. После слов Иисуса следует предложение He pa sona instcepes geseh (HomS 8 [BlHom 2]:15.25.202) - 'Он сразу же увидел вход', которое позволяет трактовать hœfp geholedne как проявление статального результата (но не динамического процесса): в вере ты пребываешь излеченным. Более того, если бы в древнеанглийском «habban + причастие II» широко использовалась с абстрактными существительными (по шкале Хоппера-Трауготт, см.: [Hopper, Traugott, 1993]), то, вероятнее всего, были бы отмечены примеры и с фиктивным подлежащим (dummy subject), выраженным местоимением it. Однако они фиксируются только в среднеанглийском (см., например: [Carey, 1994, p. 49-50, 56]).

\section{Семантическая характеристика глаголов}

Из 93 глагольных лексем лишь одна представляет собой безобъектный дуративный глагол - gerestan (отдыхать). Он употреблен в тексте Эльфрика «Жития святых», который относится к периоду 1050-1150 гг.

(16) ...pe on đam scræfe tile hwile gereste hæfdon (LS 34 [SevenSleepers]:390.284) - ' ...которые в пещере должное время отдыхали'.

Пример (16) анализируется в работе К. Кэри, посвященной истории развития перфекта в английском языке. Хотя gerestan - это глагол деятельности по классификации Вендлера (activity verb), автор, как мы полагаем, верно отмечает, что gerestan не является безобъектным, поскольку обстоятельство времени tile hwile (должное время) в данном предложении можно рассматривать как «псевдообъект» [Carey, 1994, p. 74]. Мы считаем такой подход правильным, поскольку он позво- 
ляет непротиворечиво объяснить использование флектированного причастия. Во-первых, если tile hwile, выступающее на уровне семантических ролей как сирконстант, рассматривать в качестве дополнения, то дуративный глагол деятельности трансформируется в таком случае в предельный глагол совершения по классификации Вендлера (accomplishment verb), указывающий на peзультирующее состояние, находящееся в сфере субъекта. Во-вторых, tile hwile представляет собой субстантивное словосочетание, состоящее из ядра-существительного (мн. ч. ж. p. от hwil) и согласующегося с ним прилагательного tile (должное, длительное). Отсюда появление флексии -е у причастия и его согласование с дополнением. Анализ примера (16) демонстрирует важность конкретного контекста для толкования семантики того или иного глагола.

Рассмотрим другие утверждения И. Вишер относительно употребления непредельных глаголов в анализируемой конструкции. В выборке исследователя большинство глаголов являются предельными, однако лингвист приводит 3 примера, противоречащие, по ее мнению, тезису, согласно которому глаголы (gehealdenne, gesewene, gesyngod), используемые в качестве причастия в конструкции «habban + причастие II», являются исключительно предельными [Wischer, 2004, p. 249]. Для анализа мы выбрали первые 2, поскольку они интересуют нас еще и как флектированные причастия. Рассуждая о предельности и непредельности, Б. Комри замечает, что эти семантические аспектуальные характеристики глагола зависят от контекста: в make a chair - make предельный глагол, поскольку ситуация предполагает некий конечный пункт создания стула; в John is singing - sing непредельный глагол, так как ситуация не включает подобного конечного пункта, но при этом действие, названное в John is singing a song является предельным [Comrie, 1976, p. 44-45]. Приведем пример, цитируемый И. Вишер, но в более расширенном варианте, с началом предложения, опущенного в ее цитации:

(17) he cwæđ: đæt sindan đa đa đe mid wifum ne beod besmitene, \& hira magedhad habbad gehealdenne (СР:52.409.5.2814) - 'он сказал: это те, кто женами не опорочены и свою непорочность сохранили' (досл. 'имеют сохраненной’).

В примере (17) следует обратить внимание на некоторые особенности. Несмотря на то, что глагол gehealdan действительно обозначает продолжительное действие (хранить, держать, поддерживать), конструкция «habban + причастие II» используется с прямым объектом, а глагол имеет приставку ge-, которая, как правило, выполняет телисизирующую функцию (см.: [McFadden, 2015]). Кроме того, «habban + причастие II» используется параллельно с пассивной конструкцией «beon / wesan + причастие II», включающей флектированное причастие и выражающей результирующее состояние. В совокупности эти данные указывают на то, что habbad gehealdenne в примере (17) имеет результативный характер, поскольку указывает на состояние, в котором прибывает субъект, совершивший над объектом определенное действие: неопороченные и сохранившие непорочность (те, кому удалось достичь этого результата). Подобным образом можно трактовать употребление статального глагола ge-seon (видеть) и ряд других, в частности, ge-singan в контексте с прямым дополнением:

(18) Đa hig hæfdon heora lofsang gesunggenne pa ferdon hig... (Mt [WSCp]:26.30.1877) - 'когда они свою хвалебную песнь спели (досл. 'имели спетой'), тогда отправились они...'

Аналогичные этому примеры приводит Б. Комри для иллюстрации предельности в современном английском языке. Итак, в нашей выборке все глаголы за исключением funden oт findan (находить) (имеющиеся 15 примеров употребления бесприставочного глагола findan относятся к разным периодам) используются с телесизирующей приставкой ge- или другими приставками: a-biddan (приглашать), be-fón (ловить), for-corfian (отрезать), ofer-cuman (преодолевать), of-sleán (убивать), on-lísan (освобождать). Эти приставки кроме изменения лексического значения создают предельность ситуаций, которые обозначены глаголами.

Как отмечает В.А. Плунгян, «результатив оказывается достаточно слабо грамматикализованной глагольной формой: он имеет существенные ограничения на образование 
(будучи возможен только у предельных процессов...) и хорошо предсказуемую "узкую" семантику, выводимую из лексического значения глагола» [Плунгян, 2016, с. 10]. Иными словами, глаголы, используемые с результативом, как правило, обладают семантикой изменения состояния (ср., например: [Сичинава, 2005, с. 87], где приводятся лексемы типа садиться, вешать, ломать). Действительно, кроме вышеприведенных факторов, способствующих созданию предельной ситуации, как отмечалось во многих работах, лексическая семантика глаголов, используемых в качестве флектированного причастия, способствует реализации значения предельности, поскольку глаголы обозначают: изменение состояния - a-fýlan (порочить, загрязнять), a-hón (вешать, распинать), á-hýdan (прятать), ahyrdan (затвердевать), á-weccan (воскрешать), be-lúcan (заточать, закрывать), besmitan (порочить, запятнать), ge-clcénsian (очищать), ge-búgan (сгибать), ge-liffcestan (оживлять), ge-scógan (обувать), ge-swefian (усыплять, умиротворять), ge-týnan (закрывать, прятать), ge-wyldan (укрощать, подчинять), on-lisan (освобождать); завершение действия - ge-fyllan (наполнять, выполнять, заканчивать), ge-lcéstan (выполнять, завершать); лишение / дарение - á-drifan (прогонять), aflieman (изгонять), a-drafan (прогонять), be-niman (лишать, забирать), be-ripan (обдирать, лишать), ge-niman (забирать), gesellan (отдавать); ментальные процессы (говорение, восприятие) и эмоции - gehátan (командовать, клясться), ge-leornian (учить), ge-manian (увещевать), ge-reccan (рассказывать), ge-seón (видеть), ge-wilnian (хотеть, желать); движение - ge-féran (ехать, путешествовать), ge-cyrran (поворачиваться, возвращаться). С глаголами движения используется флектированная форма причастия, но, как показано в [Бондарь, 2017], «habban + причастие II» с нефлектированной формой причастий также обладала семантикой результативности. Более того, примеры использования стативных глаголов, в частности ментальной деятельности и говорения, приводимые как доказательство наличия перфектной семантики у анализируемой конструкции (см.: [Łęcki, 2010; Wischer, 2004]), в [Carey, 1994] анализируются как результативы.

\section{Обсуждение данных}

Анализ данных показывает, что флектированные причастия в конструкции «habban + причастие II» обозначали характеристики объекта, находящегося в определенном состоянии в результате выполненного субъектом действия, или самого субъекта после совершения им определенного действия. Флектированное причастие очевидно носило адъективный характер. При этом посессивный глагол не являлся вспомогательным (как в современном перфекте). Интересно отметить, что Ю. Тойота в работе, посвященной развитию пассивной конструкции с $b e$ в английском языке, на основании критериев определения вспомогательных глаголов (auxiliaryhood), разработанных Б. Хейне, приходит к выводу о том, что $b e$ в древнеанглийском не утрачивал лексического значения и находился в стадии изменения грамматического статуса: вспомогательным глаголом он станет только в среднеанглийском [Toyota, 2008, p. 56-57, 93]. При этом уже в древнеанглийском в конструкции c beon / wesan использовались обе формы причастий (см., например, в [Mitchell, 1985, p. 311-315]).

В работе $\mathrm{P}$. Майлхаммера и Е. Смирновой древнеанглийская конструкция с глаголомсвязкой рассматривается как полностью композиционная, передающая пассивное значение в результате совмещения аспектуальных характеристик глагола-связки и аспектуальнотранзитивных характеристик второго причастия [Mailhammer, Smirnova, 2013, p. 50-61]. Отвечая на вопрос о том, можно ли говорить о грамматикализированных пассивах в древнеанглийском, и размышляя о постепенном исчезновении флексий причастий как свидетельстве грамматикализации конструкции, авторы ссылаются на то, что в древнеанглийском предикативные прилагательные имели тенденцию к нефлектированному употреблению [Mailhammer, Smirnova, 2013, p. 48].

Таким образом, вышеприведенные трактовки конструкции «beon / wesan + причастие II» позволяют понять пример (16), где обе конструкции описывают субъект и то состояние, в котором он находится (обладание результатом действия). При этом мы едва ли можем интерпретировать примеры (8), (10) и (11) как со- 
четание перфекта и результатива, тем более с однородными причастиями. В таком случае возникает вопрос: каким образом следует трактовать семантику «habban + причастие II» с нефлектированным причастием? Мы считаем, что эта конструкция выражала результативность (доказательства того, что данная конструкция имеет статально-результативный характер в большинстве контекстов см. также в [Carey, 1994; Detges, 2000]). По мнению О.А. Смирницкой, изначально (во всех древнегерманских языках) компоненты, входящие в «habban + причастие II», связаны атрибутивно-предикативной связью, а процесс отделения предикативности и атрибутивности длился многие столетия и привел «к образованию особой конструкции с переходным глаголом неполной предикации и предикативным причастием в винительном падеже» [Смирницкая, 1965, с. 5-7].

Исходя из этого, мы предлагаем рассматривать развитие связей внутри конструкции следующим образом. На начальных этапах атрибутивная характеристика причастия формировалась по модели сочетания прилагательного и существительного, а посессивный глагол выражал непосредственное владение предметом. Предикативная связь выдвигалась на первый план при расширении семантики посессивного глагола. Так, в Оксфордском словаре кроме значения непосредственного обладания у habban уже в древнеанглийский период фиксируется множество других, например:

(19) \& hæfð ðæs suiðe micelne hunger (King Ælfred tr. Gregory Pastoral Care (Hatton) (1871) xxxix. 283) (цитируется по OED) - 'и сильный голод испытывает'.

Расширение значения разрывало непосредственную атрибутивную связь причастия и дополнения, а также способствовало переосмыслению по типу предикативной связи внутри конструкции. За этим следовало и уподобление причастия прилагательному в конструкциях с предикативной связью, где прилагательные зачастую были лишены флексий. В дальнейшем «habban + причастие II» сохраняла свою общую результативную семантику. Размежевание атрибутивной и предикативной функций причастий несло и смысловые разграничения, аналогичные тем, которые прослежива- ются в прилагательных, используемых в этих функциях. При атрибутивном употреблении причастие выражает признак, который приписывается объекту как некая постоянная характеристика, при предикативном - обозначает ситуацию, указывая на временную, непостоянную, проявляемую в данном контексте черту. Это можно продемонстрировать на двух примерах, относящихся к периодам 950-1050 гг. и 1050-1150 гг. соответственно:

(20) bæt wæs dioflum sylfum, for pon pe hie hira godu hæfdon geworhte of treowum \& of stanum \& of ođrum untimbrum missenlicum (HomS 39 [ScraggVerc 12]:4.1668) - ' Это было для самого дьявола, поскольку они сделали своих богов из деревьев и камней, и различных бесполезных материалов';

(21) On pys geare, pæt wæs ymb twelf monađ pæs pe hie on pæm eastrice geweorc geworht hæfdon... (ChronA [Plummer]:894.1.1021) - 'В этот год, это было около двенадцати месяцев после того, как они построили сооружение в восточной части королевства...'

В примере (20) описание богов строится по атрибутивной модели и подчеркивает их постоянное качество: они были деревянными, каменными и т. д. В (21) предикативная модель причастия описывает ситуативный признак сооружения: завершенность строительства в определенный срок (сооружение недавно построенное). Данное разграничение позволяет объяснить употребление конструкций с обеими формами причастий в рамках одного широкого контекста и даже одного предложения (об этом см. в разделе «Синтаксическая характеристика»). Приписывание атрибутивной, постоянной характеристики объекту носило, видимо, субъективный характер и осуществлялось автором в тех контекстах, где необходимо было сделать данный акцент. Так, приводившийся уже пример (6) из Семикнижья - Bearnleasne ge habbad me gedonne (Gen:42.36.1793) - вполне можно интерпретировать с данной точки зрения: несомненно, что действие завершилось сейчас, есть его результат, но автор, по-видимому, в данном контексте счел необходимым подчеркнуть, что Яков теперь стал бездетным навсегда.

С этой же позиции необходимо рассматривать и пример (16), где, как мы уже отмечали, флектированное причастие gereste ис- 
пользовано неслучайно. Выше нами приведены синтактико-семантические аргументы в пользу такого употребления. Здесь охарактеризуем общую семантику более широкого контекста, основываясь на собственном понимании разграничений атрибутивного и предикативного употребления причастий. Согласно легенде, которая пересказывается в тексте, семеро юношей-христиан отказались выполнять приказ императора приносить жертвы языческим богам и, чтобы избежать казни, укрылись в пещере. Место, где они скрывались, обнаружили и вход в пещеру замуровали. Однако Бог сделал так, что юноши заснули долгим сном. Он разбудил их снова, когда это было необходимо (по легенде через 200 лет). В тексте говорится, что Господь, который своей мощью воскрешал мертвых и оживил Лазаря, таким же образом пробудил ото сна семерых святых, спящих в пещере. В этом свете становится понятным, что приписывание атрибутивного признака субъекту через флектированное причастие оправдано: постоянной характеристикой семерых юношей было состояние сна, которое передается словом gerestan (отдыхать, пребывать). То, что в данном случае характеристика результата действия относится не к объекту, а к субъекту, укладывается в рамки концепции К. Кэри, которая называет такие конструкции «Resultant State-Process» (peзультирующая статально-процессная конструкция). В них подлежащее находится в посессивных отношениях ('have' relation) с финальным состоянием процесса [Carey, 1994, p. 13 et passim]. Моносубъектность «habban + причастие II» отмечается и в [Смирницкая, 1965; Detges, 2000], где утверждается, что тип результатива, условно называемый Результатив II, совмещает в себе агенс и подлежащее. Хотя такая конструкция может показаться нелогичной, она существует во многих языках мира (например, исп. «tener + причастие ІІ») и является предшественником перфекта [Detges, 2000, p. 350].

\section{Выводы}

Подводя итоги, отметим наиболее важные результаты данного исследования. Выбор флектированных и нефлектированных прича- стий в рамках результативной конструкции «habban + причастие IІ» имел смысловое основание - признак субъекта-объекта: причастие с флексией указывало на длительную, имманентную характеристику описываемого предмета (аналогично атрибутивному прилагательному), а без нее - на ситуативный, временный признак прилагательного (аналогично предикативному прилагательному).

Данное разграничение действовало в рамках древнеанглийского периода при сохранении флективной системы у прилагательных и существительных, но начало подвергаться изменениям к концу древнеанглийского периода (XI-XII вв.) при общем расшатывании морфологии языка, о чем может свидетельствовать пример из текста Вульфстана.

Малая представленность флектированных причастий может быть связана с субъективным авторским взглядом и потребностями контекста.

Семантические характеристики глаголов, используемых в формах флектированных причастий, свидетельствуют о результативном значении «habban + причастие II», в рамках которой они употреблялись.

Синтаксические характеристики элементов, входящих в конструкцию с посессивным глаголом и флектированным причастием, отражают общую тенденцию их позиционного распределения в составе конструкции, за исключением превалирования постобъектных позиций причастий, которое характерно для изначальной (присущей всем германским языкам) модели с атрибутивно-предикативными связями.

\section{СПИСОК ЛИТЕРАТУРЫ}

Бондарь В. А., 2017. Habban + причастие II с глаголами движения в древнеанглийском языке // Вопросы языкознания. №. 5. С. 75-91.

Плунгян В. А., 2016. К типологии перфекта в языках мира // Acta Linguistica Petropolitana. Труды института лингвистических исследований. Т. 12 , ч. 2. C. 7-36.

Сичинава Д. В., 2005. Типология глагольных систем с синонимией базовых элементов парадигмы : дис. ... канд. филол. наук. Москва. 444 с.

Смирницкая О. А., 1965. Происхождение аналитической формы перфекта в древних германских языках : автореф. дис. ... канд. филол. наук. Москва. $18 \mathrm{c}$. 
Carey K., 1994. Pragmatics, Subjectivity and the Grammaticalization of the English Perfect : PhD dissertation. San Diego : University of California at San Diego. $165 \mathrm{p}$.

Comrie B., 1976. Aspect. Cambridge : Cambridge University Press. $142 \mathrm{p}$.

Detges U., 2000. Time and truth: The grammaticalization of resultatives and perfects within a theory of subjectification // Studies in Language. Vol. 24, № 2. P. 345-377.

Hopper P. J., Traugott E. C., 1993. Grammaticalization. Cambridge : Cambridge University Press. 276 p.

Johannsen B., 2016. From possessive-resultative to perfect? Re-assessing the meaning of [hæbb- + past participle] constructions in Old English prose // Re-assessing the Present Perfect / V. Werner, E. Seoane, C. Suárez-Gómez (eds). Berlin ; Boston : Walter de Gruyter GmbH. P. 23-41.

Kilpiö M., 2013. Causative habban in old English // Comparative Studies in Early Germanic Languages: With a focus on verbal categories. T. 138. P. 101-125.

Lee J.-H., 2004. Periphrastic Perfect Tense in English: A Historical Perspective. Dissertation. Austin : The University of Texas at Austin. 225 p.

Łęcki A., 2010. Grammaticalisation Paths of «Have» in English. Series: Studies in English Medieval Language and Literature. Vol. 24. Frankfurt am Main : Peter Lang. 269 p.

Lussky G. F., 1922. The Verb Forms Circumscribed with the Perfect Participle in the Beowulf// The Journal of English and Germanic Philology. Vol. 21, № 1. P. 32-69.

Mailhammer R., Smirnova E., 2013. Sources of passive constructions in Old High German and Old English // Comparative Studies in Early Germanic Languages. With a focus on verbal categories / G. Diewald, L. Kahlas-Tarkka, I. Wischer (eds.). Amsterdam: John Benjamins Publishing Company. P. 41-70.

McFadden Th.,2015. Preverbal ge- in Old and Middle English. URL: http://www.zas.gwz-berlin.de/ fileadmin/mitarbeiter/mcfadden/ge writeup.pdf (дата обращения: 19.01.2018).

Mitchell B., 1985. Old English Syntax. Vol. I. Oxford : Clarendon. $820 \mathrm{p}$.

Toyota J., 2008. Diachronic change in the English passive. Springer. $286 \mathrm{p}$.

Traugott E. C., 1992. Syntax // The Cambridge history of the English language / R. M. Hogg (ed.). Cambridge : Cambridge University Press. P. $168-289$.

Wischer I., 2004. The HAVE- 'perfect' in Old English // New Perspectives on English Historical Linguistics. Selected Papers from 12 ICEHL (Glasgow, 21-26 August 2002) / Ch. Kay (ed.).
Vol. 1: Syntax and Morphology. Philadelphia : John Benjamins Publishing Company. P. 243-255.

Yao X., 2015. The present perfect and the preterite in Australian English // Grammatical Change in English World-Wide (Studies in Corpus Linguistics, 67) / P. Collins (ed.). Amsterdam : John Benjamins Publishing Company. P. 247-268.

\section{ИСТОЧНИКИ}

OED - Oxford English Dictionary online. URL: http:// www.oed.com (дата обращения: 18.01.2018).

The York-Toronto-Helsinki Parsed Corpus of Old English Prose - The York-Toronto-Helsinki Parsed Corpus of Old English Prose (YCOE) /A. Taylor,A. R. Warner, S. Pintzuk, F. Beths. York : University of York : Department of Linguistics, 2003. P. 196-227.

\section{REFERENCES}

Bondar V.A., 2017. Habban + Participle II with the Verbs of Motion in old English. Voprosy yazykoznaniya [Topics in the Study of Language], no. 5, pp. 75-91.

Plungyan V.A., 2016. Toward the Typology of the Perfect Tense in the World Languages. Acta Linguistica Petropolitana. Trudy instituta lingvisticheskikh issledovaniy, vol. 12, part 2, pp. 7-36.

Sichinava D.V., 2005. The Typology of Verbal Systems with the Synonymy of the Paradigm's Basic Elements. Cand. philol. sci. diss. Moscow. 444 p.

Smirnitskaya O.A., 1965. The Origin of the Analytical Form of the Perfect in the Ancient Germanic Languages. Cand. philol. sci. abs. diss. Moscow. 18 p.

Carey K., 1994. Pragmatics, Subjectivity and the Grammaticalization of the English Perfect. PhD dissertation. University of California at San Diego. $165 \mathrm{p}$.

Comrie B., 1976. Aspect. Cambridge, Cambridge University Press. 142 p.

Detges U., 2000. Time and truth: The grammaticalization of resultatives and perfects within a theory of subjectification. Studies in Language, vol. 24, no. 2, pp. 345-377.

Hopper P.J., Traugott E.C., 1993. Grammaticalization. Cambridge, Cambridge University Press. 276 p.

Johannsen B., 2016. From possessive-resultative to perfect? Re-assessing the meaning of [Habban- + past participle] constructions in Old English prose. Werner, V., Seoane, E., Suárez-Gómez C., 
B.A. Бондарь. Перфект и формы второго причастия в древнеанглийском языке

eds. Re-assessing the Present Perfect. Berlin; Boston, Walter de Gruyter GmbH, pp. 23-41.

Kilpiö M., 2013. Causative habban in old English. Comparative Studies in Early Germanic Languages: With a focus on verbal categories, vol. 138, pp. 101-125.

Lee J.-H., 2004. Periphrastic Perfect Tense in English: A Historical Perspective. Dissertation. The University of Texas at Austin. 225 p.

Łęcki A., 2010. Grammaticalisation Paths of 'Have' in English. Series: Studies in English Medieval Language and Literature. Frankfurt am Main, Peter Lang, vol. 24. 269 p.

Lussky G. F., 1922. The Verb Forms Circumscribed with the Perfect Participle in the Beowulf. The Journal of English and Germanic Philology, vol. 21, no. 1, pp. 32-69.

Mailhammer R., Smirnova E., 2013. Sources of passive constructions in Old High German and Old English. Diewald G., Kahlas-Tarkka L., Wischer I. (eds.). Comparative Studies in Early Germanic Languages. With a focus on verbal categories. Amsterdam, John Benjamins Publishing Company, pp. 41-70.

McFadden Th. Preverbal ge- in Old and Middle English. URL: http://www.zas.gwz-berlin.de/ fileadmin/mitarbeiter/mcfadden/ge_writeup.pdf (accessed 19 January 2018).
Mitchell B., 1985. Old English Syntax. Oxford, Clarendon, vol. I. 820 p.

Toyota J., 2008. Diachronic change in the English passive. Springer. $286 \mathrm{p}$.

Traugott E.C., 1992. Syntax. Hogg R.M., ed. The Cambridge history of the English language. Cambridge, Cambridge University Press, pp. 168-289.

Wischer I., 2004. The HAVE-'perfect' in Old English. Kay Ch., ed. New Perspectives on English Historical Linguistics. Selected Papers from 12 ICEHL (Glasgow, 21-26 August 2002). Vol. 1: Syntax and Morphology. Philadelphia, John Benjamins Publishing Company, pp. 243-255.

Yao X., 2015. The Present Perfect and the Preterite in Australian English. Collins P., ed. Grammatical Change in English World-Wide (Studies in Corpus Linguistics, 67). Amsterdam, John Benjamins Publishing Company, pp. 247-268.

\section{SOURCES}

Oxford English Dictionary online. URL: http:// www.oed.com (accessed 18 January 2018).

Taylor A., Warner A. R., Pintzuk S., Beths F., 2003. The York-Toronto-Helsinki Parsed Corpus of Old English Prose (YCOE). York, University of York, Department of Linguistics, pp. 196-227.

\section{Information about the Author}

Vladimir A. Bondar, Candidate of Sciences (Philology), Associate Professor of Department of English for Academic and Business Communication, Saint Petersburg State University, Universitetskaya Emb., 7-9, 199034 Saint Petersburg, Russia, alstar@inbox.ru, https://orcid.org/0000-0001-7636-0326

\section{Информация об авторе}

Владимир Анатольевич Бондарь, кандидат филологических наук, доцент кафедры делового иностранного языка, Санкт-Петербургский государственный университет, наб. Университетская, 7-9, 199034 г. Санкт-Петербург, Россия, alstar@inbox.ru, https://orcid.org/0000-0001-7636-0326 